\title{
Detection of the effects of ingested caffeine on fertility of cocks by homospermic and heterospermic insemination
}

\author{
D. R. Hagen* and P. J. Dziuk \\ Department of Animal Science, University of Illinois, Urbana, Illinois 61801, U.S.A.
}

\begin{abstract}
Summary. Cocks were fed diets containing $0,0.025,0.05,0.075$ or $0.1 \%$ caffeine during a 14-day treatment period. The number of spermatozoa produced by cocks fed 0.075 or $0.1 \%$ caffeine declined sharply at 12 days after onset of treatment. Hens were inseminated with a constant number of spermatozoa from individual cocks. The fertility of cocks fed $0.05,0.075$ or $0.1 \%$ caffeine declined during the 17-day post-treatment period and then returned to pretreatment levels.

Cocks whose offspring were distinguishable were paired and relative fertility was assessed in a heterospermic test. One cock in each pair was fed $0.05 \%$ caffeine during the treatment period. Hens were inseminated with semen mixed within pairs. The proportion of chicks sired by cocks fed caffeine decreased during treatment and remained at that level until 17 days after treatment, when it increased to pretreatment levels. The percentage of total eggs hatched declined concomitantly with the reduction in the proportions of chicks sired by treated cocks.

These results indicate that the effect of low levels of a toxin could be detected by reduced numbers of eggs hatched after heterospermic insemination with semen of normal appearance.
\end{abstract}

\section{Introduction}

Fertility differs between males and from time to time in the same male and may be affected by the exposure of the male to toxins. Among tests used for evaluating fertility are the homospermic test, in which one male inseminates several females, and the heterospermic test, in which spermatozoa from two males compete in one female. Cole \& Davis (1914) tested for the effect of ingested alcohol on fertility in males by means of competitive fertilization. Roberts \& Dawson (1935) used competitive fertilization to test for the effect of Fowler's solution, which contains arsenic, on fertility in rabbits. During the past 10 years competitive fertilization has been used to test for the effect of methods of handling semen (O'Reilly, Graves \& Dziuk, 1972) but there have been no reports on the usefulness of this test to measure the effect of environmental factors or toxins on fertility. In the present study we examined the effect of dietary caffeine $(1,3,7$ trimethyl xanthine) on the fertility of cocks because caffeine is known to induce reversible azoospermia and sterility in cocks (Ax, Collier \& Lodge, 1976). The results have been briefly reported in abstract form (Hagen \& Dziuk, 1979).

* Present address: Department of Dairy and Animal Science, The Pennsylvania State University, University Park, Pennsylvania 16802 , U.S.A. 


\section{Materials and Methods}

Preliminary trial. This was undertaken to determine a level of dietary caffeine which would reduce male fertility without affecting sperm output. Ten mature Columbian and New Hampshire cocks (Gallus domesticus) weighing 5-7 kg were assigned at random, 2 cocks per group, to 1 of 5 treatments. The treatments were standard poultry diets containing $0,0.025$, $0.05,0.075$ or $0.1 \%$ caffeine by weight. Each cock was caged separately and food and water were freely available. Food intake was measured. Each cock served as its own control with a 10-day pretreatment period to establish a baseline being followed by the treatment for 14 days, a period equivalent to the duration of spermatogenesis in the cock (de Reviers, 1968). The control diet was then given for a post-treatment period of 17 days. Any effects of the treatment on sperm maturation were therefore expected during the first 14 days of the post-treatment period, while spermatozoa formed after the treatment would be unaffected.

Semen was collected by massage (Burrows \& Quinn, 1937) from each cock twice weekly at 13:30 $\mathrm{h}$. The volume of each ejaculate was determined and the concentration of spermatozoa established with a haemocytometer. The semen was diluted to a concentration of $10^{9} \mathrm{cells} / \mathrm{ml}$ in TC199 (Grand Island Biological, New York, U.S.A.) (Ax \& Lodge, 1975). Five hens were immediately, i.e. within $2 \mathrm{~h}$ of semen collection, inseminated intravaginally with $10^{8}$ spermatozoa from individual cocks (Day 0 ).

The interval between consecutive inseminations of any one hen was at least 21 days. Eggs laid from Day 2 to Day 12 after the single insemination were gathered, marked for identification, and then set at weekly intervals in an incubator maintained at $37^{\circ} \mathrm{C}$. Eggs were candled on the 7 th day of incubation to identify the fertile eggs.

Data on the proportions of eggs fertile on the 7 th day of incubation were analysed by the method of Yates (1937) for factorial experiments. The proportion of eggs fertilized was transformed by angular transformation (Steel \& Torrie, 1960).

Experimental study. The effect of caffeine on the relative fertility of males was tested at a dose level established from the preliminary trial. Six pairs of Columbian and New Hampshire cocks, whose offspring were morphologically distinguishable, were the experimental animals. The relative innate difference between cocks of each pair was determined by heterospermic insemination of a mixture of equal numbers of spermatozoa from both cocks into sufficient hens to yield at least 40 chicks. The proportions of resultant chicks sired by each cock were determined at hatching. From these results the ratios of spermatozoa from the cocks were adjusted in the subsequent mixtures so that each cock would sire approximately $50 \%$ of the offspring to increase the sensitivity of the test (Martin, Reimers, Lodge \& Dziuk, 1974).

Semen and eggs were handled as in the preliminary trial, and hens were inseminated intravaginally with mixed, diluted semen. On the 19 th day of incubation, the eggs were transferred to a hatcher and separated so that each chick could be identified with the number on the shell and its paternity established at hatching (Martin et al., 1974). Chicks were identified with numbered wing-bands and paternity was verified at 5 days of age. The experimental period included a 20-day pretreatment period when baseline proportions of offspring from each cock in each pair were established; a treatment period of 14 days, during which one cock in each pair (the Columbian cock in 3 of the pairs, the New Hampshire cock in the others) was fed a diet containing $0.05 \%$ caffeine by weight; and a 29 -day period, which was subdivided into a 17 -day segment and a 12-day recovery segment. There were 3779 eggs incubated.

Data were analysed by the method of Yates (1937) and by the method of Brandt \& Snedecor (Snedecor, 1956).

\section{Results}

The mean daily food consumption per cock was $111 \mathrm{~g}$. There were no differences among 
treatment groups in the amount of food consumed $(P>0.05)$, indicating no effect of caffeine on appetite, acceptability of the diet, or on the general health of the animals.

Preliminary trial. One of the two cocks fed $0.075 \%$ caffeine and both cocks fed $0.1 \%$ caffeine became azoospermic 21 days after the initiation of treatment, but spermatozoa reappeared in the ejaculate 12 days after withdrawal of caffeine from the diet. Sperm output did not change in the other groups during the period $(P>0.05)$ (Table 1). The proportions of fertile eggs for cocks fed no caffeine were variable during the treatment period. The proportion of eggs fertilized from hens inseminated with semen from cocks fed $0.05,0.075$ or $0.1 \%$ caffeine was lower $(P<0.05)$ during the 17 -day post-treatment period than during the pretreatment period (Table 2). Fertility was restored to pretreatment levels by 12 days after withdrawal of the diet containing caffeine.

Table 1. The numbers of spermatozoa per ejaculate $\left(\times 10^{8}\right)$ from cocks fed caffeine at various levels for 14 days

\begin{tabular}{|c|c|c|c|}
\hline \multirow{2}{*}{$\begin{array}{c}\text { Dietary caffeine } \\
(\%)\end{array}$} & \multicolumn{3}{|c|}{ Period } \\
\hline & Pretreatment & Treatment & Post-treatment \\
\hline 0 & $15 \cdot 7 \pm 3 \cdot 5$ & $15 \cdot 4 \pm 3 \cdot 2$ & $24 \cdot 2 \pm 7 \cdot 2$ \\
\hline 0.025 & $13.3 \pm 2.0$ & $15.8 \pm 0.7$ & $20.8+2.3$ \\
\hline 0.05 & $19.1 \pm 4.4$ & $22 \cdot 6 \pm 3 \cdot 3$ & $15 \cdot 6 \pm 2.5$ \\
\hline 0.075 & $9.8 \pm 0.5$ & $15.2 \pm 1.8^{*}$ & $7.0+1.7$ \\
\hline 0.1 & $9.9 \pm 0.6$ & $13.9 \pm 0.6^{*}$ & $3.8 \pm 2 \cdot 4^{*}$ \\
\hline
\end{tabular}

Values are means \pm standard error of 2 replicates.

$* P<0.05$ compared to other values for that dose of caffeine.

Table 2. Percentage of eggs fertile (no. of eggs incubated in parentheses) on the 7th day of incubation after insemination with semen from cocks fed caffeine

\begin{tabular}{cccc}
\hline \multirow{3}{*}{$\begin{array}{c}\text { Dietary caffeine } \\
(\%)\end{array}$} & Pretreatment & Treatment & Post-treatment \\
\cline { 2 - 4 } & $55.5(220)$ & $52.9(206)$ & $35.9(145)^{*}$ \\
0.05 & $66.3(249)$ & $55.8(258)$ & $36.7(158)^{*}$ \\
0.075 & $47.4(95)^{*}$ & $32.1(131)$ & $21.6(37)$ \\
0.1 &
\end{tabular}

${ }^{*} P<0.05$ compared to other values for that dose of caffeine.

Table 3. Effect of $0.05 \%$ dietary caffeine fed to one cock in each of 6 pairs on the result of heterospermic insemination

\begin{tabular}{lcccc}
\hline & \multicolumn{4}{c}{ Period } \\
\cline { 2 - 5 } & Pretreatment & Treatment & Post-treatment & Recovery \\
\hline $\begin{array}{l}\text { No. of eggs incubated } \\
\text { \% of eggs fertile on Day } 7\end{array}$ & 1514 & 813 & 863 & 589 \\
$\begin{array}{l}\text { No. of chicks sired by } \\
\text { treated cocks/no. sired }\end{array}$ & $53 \cdot 3$ & $47 \cdot 1$ & $41 \cdot 4^{*}$ & 48.0 \\
$\begin{array}{l}\text { by untreated cocks } \\
\begin{array}{l}\text { of total chicks sired } \\
\text { by treated cocks }\end{array}\end{array}$ & $367 / 289$ & $128 / 199$ & $108 / 258$ & $133 / 112$ \\
\hline
\end{tabular}

* Significantly different from other values, $P<0.005$.

$\dagger$ Significantly different from pretreatment and recovery values, $P<0.05$. 
Experimental study. The results from the 6 pairs of cocks in this study were similar and were combined for analysis. Considerable variation in sperm output was noted between cocks within treatment groups but no differences $(P>0 \cdot 10)$ were noted among periods of the experiment. There was a reduction in the numbers of eggs fertile on the 7 th day of incubation (and hence of hatching rate) during the post-treatment period but pretreatment values were regained later (Table 3). The treated cocks did, however, sire fewer chicks during the treatment and post-treatment periods (Table 3).

\section{Discussion}

Caffeine, at the levels fed, had no readily apparent effect on appetite or general well-being of the cocks. Cocks fed 0.075 or $0.1 \%$ caffeine became azoospermic during the post-treatment period confirming the observation of the previous study (Ax et al., 1976). This reduction in sperm production was temporary and reversible, however. When the caffeine was removed from the diet and the 14-day period equivalent to the spermatogenic cycle had elapsed, sperm output returned to normal. The temporary azoospermia and subsequent recovery indicates that meiosis was inhibited at an early stage, perhaps in replication of DNA at prophase (Wragg, Carr \& Ross, 1967). Sperm production was not reduced until at least 14 days after initiation of treatment, indicating that caffeine does not adversely affect spermatozoa after the initial stages of formation. Reversibility of the effect is required for male contraceptives, and investigation of compounds like caffeine with an effect on sperm production but no untoward side effects might be useful.

Cocks fed $0.05,0.075$ or $0.1 \%$ caffeine had a reduced fertility during the post-treatment period in spite of inseminations with a constant number of apparently normal spermatozoa. The reduction in fertility coincided with the time of reduced sperm output. It appears that caffeine not only interferes with the numbers of spermatozoa produced but also with their fertilizing ability. This observation could be useful to test potential environmental toxins.

When semen from pairs of cocks was mixed within pairs and inseminated in a heterospermic test, there was a reduction in the proportion of eggs judged fertile after 7 days of incubation during the post-treatment period even though only one member of the pair was treated. This observation was unexpected in a heterospermic test. If spermatozoa from a treated cock were affected adversely and thus could not compete effectively in fertilizing eggs, the spermatozoa from the untreated cock would be expected to fertilize a higher proportion of eggs to give an essentially unchanged proportion of total eggs fertilized. One explanation for the observed reduction could be that the spermatozoa from caffeine-treated cocks were capable of initial activation of fertilization of the ova but that development failed thereafter. Another possible reason for the reduction in fertility would be a lack of sufficient spermatozoa in the inseminate from untreated cocks. However, the ratios of spermatozoa provided by the cocks in a pair were never greater than $5: 1$, and so neither cock contributed fewer than $16.6 \times 10^{6}$ spermatozoa to an inseminate. Moreover, Martin \& Dziuk (1977) reported that good fertility could be obtained with only $3.125 \times 10^{6}$ spermatozoa per hen using chickens from the same source as in these experiments.

The change in the proportions of chicks hatched that were sired by treated cocks indicate that possibly two factors were acting. (1) The spermatozoa from treated cocks were not competing with spermatozoa from untreated cocks even though the numbers of spermatozoa in the semen mixtures were not changed. (2) The spermatozoa collected from treated males during the treatment and early post-treatment periods may have been able to fertilize the egg but unable to effect further embryonic development.

Whatever the reason for the effect, it was reversible because the values for the recovery period were similar to those in the pretreatment period.

Cole \& Davis (1914) and Roberts \& Dawson (1935) reported that toxins caused a reduction in the proportion of offspring sired by the treated males in competition with untreated males, 
showing the potential usefulness of heterospermic tests. The levels of toxins had a general systemic effect on the males and the importance of the proportion of spermatozoa contributed by each male on the proportion of offspring sired had not been recognized (Martin et al., 1974). In the present experiment, each cock contributed a known proportion of the total spermatozoa inseminated throughout the experiment, so any change in the proportion of chicks sired by that cock could be attributed to a change in the ability of each of those spermatozoa to compete with each of those of the other cock. The effects of the caffeine in these experiments were not detectable by gross observation of the male or his semen.

The findings of these experiments show that the technique of heterospermic insemination has potential as a method for screening various substances for potentially harmful effects on fertility. At present, such substances must be tested by treating the males with the substance and then mating these males to many females at various intervals. Major effects can be detected by such homospermic matings but the many sources of variation associated with this method, including season, inseminator, breed, level of nutrition, and the effect of the female, reduce the chances of detecting subtle effects and the sensitivity of the tests. Therefore, a very large number of inseminations must be performed to detect even potentially large effects on fertility. The use of heterospermic insemination would eliminate these sources of error because the spermatozoa compete against each other in one female under the same conditions. The technique of heterospermic insemination is more than $\mathbf{1 7 0}$ times as efficient as homospermic insemination for detecting the difference in fertility between males (Beatty, Bennett, Hill, Hancock \& Stewart, 1969) and the differences are repeatable within pairs of males over time (Martin et al., 1974). These characteristics are further support for the potential of this method as a reliable, valuable and practical adjunct to those used at present for testing the effect of various materials on fertility. The chicken was used as a model in these experiments because of the short reproductive cycle in both the male and female. Other heterospermic insemination studies conducted previously with mammals indicate that the conclusions drawn from the present experiments may also be applicable to male mammals.

D.R.H. was an NIH predoctoral trainee.

\section{References}

Ax, R.L. \& Lodge, J.R. (1975) Rooster spermatozoa mobility, forward progression, and fertility after storage at $25^{\circ}, 5^{\circ}$, or $-196^{\circ}$ in various extenders. Cryobiology 12, 93-97.

Ax, R.L., Collier, R.J. \& Lodge, J.R. (1976) Effects of dietary caffeine on the testis of the domestic fowl, Gallus domesticus. J. Reprod. Fert. 47, 235-238.

Beatty, R. A., Bennett, G.A., Hill, J.G., Hancock, J.L. \& Stewart, D.L. (1969) An experiment with hetero spermic insemination in cattle. J. Reprod. Fert. 19, 491-502.

Burrows, W.H. \& Quinn, J.P. (1937) The collection of spermatozoa from the domestic fowl and turkey. Poult. Sci. 16, 19-24.

Cole, L.J. \& Davis, C.L. (1914) The effect of alcohol on the male germ cell; studied by means of double matings. Science, N.Y. 39, 476-477.

de Reviers, M. (1968) Determination de la durée des processus spermatogenetiques chez le coq à l'aide de thymidine tritiée. Proc. 6th Int. Congr. Reprod. \& A.I., Paris, vol. 1, pp. 183-185.

Hagen, D.R. \& Dziuk, P.J. (1979) Heterospermic insemination as a means for detecting the effects of treatment on male fertility. J. Anim. Sci. 49, Suppl. 1, 300-301, Abstr. 393.
Martin, P.A. \& Dziuk, P.J. (1977) Assessment of relative fertility of males (cockerels and boars) by competitive mating. J. Reprod. Fert. 49, 323-329.

Martin, P.A., Reimers, T.J., Lodge, J.R. \& Dziuk, P.J. (1974) The effect of ratios and numbers of spermatozoa mixed from two males on proportions of offspring. J. Reprod. Fert. 39, 251-258.

O'Reilly, P.J., Graves, C.N. \& Dziuk, P.J. (1972) Heterospermic insemination of rabbit semen as a means of evaluating techniques of semen handling. $J$. Reprod. Fert. 29, 49-56.

Roberts, E. \& Dawson, W.M. (1935) Effect of Fowler's solution on animals. Bull. Ill. Agr. Exp. Stn, No. 413.

Snedecor, G.W. (1956) Statistical Methods, 5th edn. Iowa State University Press, Ames.

Steel, R.G.D. \& Torrie, J.H. (1960) Principles and Procedures of Statistics. McGraw-Hill, New York.

Wragg, J.B., Carr, J.V. \& Ross, V. (1967) Inhibition of DNA polymerase activity by caffeine in a mammalian cell line. J. Cell Biol. 35, 146a.

Yates, F. (1937) The design and analysis of factorial experiments. Tech. Commun. Imp. Bur. Soil Science 35. 